\title{
Encoding tasks and free recall in children
}

\author{
THOMAS C. LORSBACH and JOHN H. MUELLER \\ University of Missouri, Columbia, Missouri 65211
}

\begin{abstract}
In two experiments, children were compared on recall following orienting tasks that involved attention to semantic or nonsemantic features of words. In Experiment 1, young children benefited from a semantic task as much as older children, compared to a nonsemantic task, but younger children still recalled fewer words after either task. In Experiment 2, subjects had experience with various versions of tasks at the same level, then were transferred to a task that required no overt orienting decision. There was no evidence that experiences derived from overt classifications were spontaneously carried over to benefit general memory performance. This suggests that the benefits of semantic over nonsemantic orienting tasks are due to the automatic by-products that result for different types of orienting tasks, rather than to the priming of generalizable strategies.
\end{abstract}

Considerable attention has been devoted to the analysis of the development of memory in children (e.g., Brown, 1979; Jablonski, 1974). Much of this activity has been concerned with the features that children encode at different ages. The growth of semantic encoding with age is conceptually compatible with the levels-of-processing view of memory (Craik, 1977). This model conceives memory as tied to perceptual processing, with the preliminary stages of stimulus analysis directed to physical features and the later stages concerned with semantic content. It is generally presumed that more durable memory traces result from deeper semantic processing. There is considerable evidence (e.g., Hyde \& Jenkins, 1973) that orienting tasks involving deep features (e.g., pleasantness judgments) produce more durable memory traces in adults than tasks involving sensory attributes (e.g., letter detection).

The general increase in recall with age is consistent with increased semantic encoding by older children. One reason for the young child's performance deficit in free recall may be perseveration on superficial physical features at the expense of semantic processing. If so, age differences in recall should be reduced when a "deep" orienting task is required, as young children would then process in a manner comparable to that of older children. This, of course, assumes that the semantic processing deficit is a failure to engage in such processing spontaneously, rather than competence per se. If a mediation rather than a production deficiency is involved (cf. Flavell, 1970), a semantic orienting task would not help younger children.

The present experiments concerned the effect of orienting tasks on children's intentional learning. Recent

Requests for reprints should be sent to J.H. Mueller, Psychology Department, 210 McAlester Hall, University of Missouri, Columbia, Missouri 65211. The authors wish to acknowledge Patricia Sheehan, for serving as experimenter, and the helpful comments on an earlier draft by Donald Kausler and Jane Rankin. incidental learning studies have generally found superior performance after deep tasks (e.g., Murphy \& Brown, 1975), but the results are mixed with regard to age differences. Geis and Hall (1976) found no qualification of the semantic-nonsemantic task difference as a function of age (i.e., no Age by Task interaction), consistent with a production deficiency view. Weiss, Robinson, and Hastie (1977) found an interaction, with the deep task helpful only for older children, in accord with a mediation deficiency view. On the other hand, Sykes (1976) found that the advantage of deep over shallow processing was greatest for younger children (using a recognition test). Finally, Waters and Waters (1976), in a study of multitrial intentional recall, found that deep tasks helped younger children only when the task was constantly performed, in accord with a deficiency in spontaneous utilization.

To provide another perspective on age differences in depth of processing, this research also examined whether recency effects in immediate and final recall were the same in children and adults. Whereas adults generally recall recency items better than middle or primacy items on an immediate test, final recall generally shows "negative" recency, presumably because the recency items were not thoroughly processed originally (Craik, 1977). If young children normally process superficially at all input positions, their final recall deficit relative to older children should be more apparent for early input items (since young and old alike process recency items shallowly).

The first experiment involved the presentation of several free recall lists, with a single test on each, and a final recall test for all items. During the study phase, subjects made a classification decision for each word in the list.

\section{EXPERIMENT 1}

\section{Method}

Subjects and Design. The subjects were 36 students attending the Laboratory School at the University of Missouri. The average 
ages were 7.7, 9.5, and 11.6 years for Grades 2, 4, and 6, respectively. The design was a 3 by 3 mixed factorial, with grades as the between-subject factor and task (like, taxonomic, voice) as the within-subject factor, with six boys and six girls in each grade.

Materials. Three 10-word lists and one 10-word practice list were constructed by choosing 40 words from the 20 most frequent responses to two categories in the Battig and Montague (1969) norms. Half of the words in each list were instances of vegetables and half were fruits. The words were tape-recorded for presentation at a 5 -sec rate, with half of the words in each list read in a male voice and the other half in a female voice. The order of item types (i.e., categories and voices) was random in each list.

Immediate free recall. Each subject received the practice list (no orienting task) followed by the three unrelated test lists. The test lists were presented by giving the subject specific instructions for the classification task used for all words in that list. The subject listened to each item, pronounced it aloud, and then rendered the decision aloud. A $60-\mathrm{sec}$ oral recall test followed each list. The orienting tasks required classification according to (1) whether the voice was a man's or a woman's (voice task), (2) whether the word was a fruit or a vegetable (taxonomic task), or (3) whether the subject "liked" or "disliked" the word (like task). The sequence of the three tasks was randomized for each subject.

Final free recall. After the third test, each subject was required to complete three math problems as a filler task. The subject was then informed of the final recall test and given $3 \mathrm{~min}$ to recite as many words as possible from all three lists.

\section{Results}

The probability of recall (Table 1) was computed in terms of separate input segments to simplify interpretation. The primacy segment was defined as Input Positions 1-2, the recency segment was Positions 9-10, and the middle segment was Positions 3-8. Position was included in the analysis as a repeated-measures factor. Effects described as significant involve $\mathrm{p}<.05$.

Immediate recall. Only the three main effects were significant. The grade main effect $[\mathrm{F}(2,33)=14.74$, $\mathrm{MSe}=.09]$ revealed that sixth graders recalled more than fourth graders, who in turn recalled more than second graders $(\mathrm{M}=.63, .53$, and .41 , respectively $)$. The task main effect $[\mathrm{F}(2,66)=11.55, \mathrm{MSe}=.07]$ revealed that the voice task was worse than both the taxonomic and like tasks $(M=.43, .55$, and .59 , respec- tively). The position main effect $[\mathrm{F}(2,66)=14.89$, $\mathrm{MSe}=.10]$ merely indicated the expected superior recall of recency items, followed by primacy and middle items (which did not differ).

Short-term store recall. One aspect of age-related differences in recall concerns the extent to which the effects are due to the development of long- vs. shortterm storage (STS). An item was considered recalled from STS if fewer than seven input and/or output events intervened (Tulving \& Colotla, 1970). In terms of the number of items recalled from STS, there was a grade main effect $[\mathrm{F}(2,33)=4.34, \mathrm{MSe}=.77]$, as sixth graders recalled more than fourth and second graders, the latter two being comparable. There was no task main effect and no Grade by Task interaction (Fs $<1.31)$.

To assess this strategy further, we computed the proportion of total recall derived from STS. The grade main effect was significant $[\mathrm{F}(2,33)=3.93, \mathrm{MSe}=.05]$, as second graders relied more on STS recall than fourth and sixth graders, the latter two groups being comparable. This indicates that the age increment in total recall involved increasing reliance on long-term memory, whether or not the size of STS increased. (There is, of course, a potential problem with using a fixed value for computing the Tulving-Colotla measure when in fact that capacity might increase with age.) The task main effect was also significant $[\mathrm{F}(2,66)=5.09, \mathrm{MSe}=.04]$. The voice task led to higher proportions of STS recall than the like and taxonomic tasks (which did not differ). If the STS strategy reflects superficial processing, this pattern of results would be expected. There was no Grade by Task interaction $(\mathrm{F}<1)$.

Final recall. The grade main effect $[F(2,33)=7.78$, $\mathrm{MSe}=.17]$ showed that sixth graders recalled more than fourth graders, who recalled more than second graders $(\mathrm{M}=.45, .37$, and .23 , respectively). The task main effect $[F(2,66)=12.06, \quad \mathrm{MSe}=.13]$ revealed superior recall in the like and taxonomic conditions, compared to the voice condition $(M=.43, .42$, and .21 , respectively). No other effects were significant $($ Fs $<1.28)$. Grade and task main effects were also apparent when final recall was conditionalized on

Table 1

Average Probability of Recall by Input Segment for Immediate and Final Tests and Recall from Short-Term Storage (STS) During the Immediate Tests, by Orienting Task and Grade

\begin{tabular}{|c|c|c|c|c|c|c|c|c|c|c|c|c|c|c|c|c|c|c|}
\hline & \multicolumn{9}{|c|}{ Immediate Free Recall } & \multicolumn{9}{|c|}{ Final Free Recall } \\
\hline & \multicolumn{3}{|c|}{ Voice } & \multicolumn{3}{|c|}{ Like } & \multicolumn{3}{|c|}{ Taxonomic } & \multicolumn{3}{|c|}{ Voice } & \multicolumn{3}{|c|}{ Like } & \multicolumn{3}{|c|}{ Taxonomic } \\
\hline & 2 & 4 & 6 & 2 & 4 & 6 & 2 & 4 & 6 & 2 & 4 & 6 & 2 & 4 & 6 & 2 & 4 & 6 \\
\hline $\begin{array}{l}\text { Primacy } \\
\text { Middle } \\
\text { Recency }\end{array}$ & $\begin{array}{l}.21 \\
.25 \\
.46\end{array}$ & $\begin{array}{l}.33 \\
.29 \\
.67\end{array}$ & $\begin{array}{l}.46 \\
.47 \\
.71\end{array}$ & $\begin{array}{l}.46 \\
.39 \\
.67\end{array}$ & $\begin{array}{l}.58 \\
.46 \\
.79\end{array}$ & $\begin{array}{l}.63 \\
.53 \\
.79\end{array}$ & $\begin{array}{l}.33 \\
.39 \\
.50\end{array}$ & $\begin{array}{l}.46 \\
.53 \\
.67\end{array}$ & $\begin{array}{l}.79 \\
.64 \\
.63\end{array}$ & $\begin{array}{l}.13 \\
.15 \\
.08\end{array}$ & $\begin{array}{l}.13 \\
.26 \\
.25\end{array}$ & $\begin{array}{l}.29 \\
.31 \\
.29\end{array}$ & $\begin{array}{l}.25 \\
.18 \\
.38\end{array}$ & $\begin{array}{l}.38 \\
.47 \\
.42\end{array}$ & $\begin{array}{l}.63 \\
.44 \\
.71\end{array}$ & $\begin{array}{l}.29 \\
.26 \\
.38\end{array}$ & $\begin{array}{l}.50 \\
.43 \\
.50\end{array}$ & $\begin{array}{l}.50 \\
.46 \\
.42\end{array}$ \\
\hline Total & .31 & .43 & .55 & .50 & .61 & .65 & .41 & .55 & .69 & .12 & .21 & .30 & .27 & .42 & .59 & .31 & .48 & .46 \\
\hline $\begin{array}{l}\text { STS-Number } \\
\text { STS-Proportion }\end{array}$ & $\begin{array}{r}1.83 \\
.68 \\
\end{array}$ & $\begin{array}{r}2.08 \\
.61 \\
\end{array}$ & $\begin{array}{r}3.00 \\
.59 \\
\end{array}$ & $\begin{array}{r}2.41 \\
.54 \\
\end{array}$ & $\begin{array}{r}2.33 \\
.46 \\
\end{array}$ & $\begin{array}{r}2.42 \\
.42 \\
\end{array}$ & $\begin{array}{r}2.25 \\
.64 \\
\end{array}$ & $\begin{array}{r}2.50 \\
.48 \\
\end{array}$ & $\begin{array}{r}2.83 \\
.44 \\
\end{array}$ & & & & & & & & & \\
\hline
\end{tabular}


immediate recall $[\mathrm{F}(2,33)=3.70, \quad \mathrm{MSe}=.35$, and $\mathrm{F}(2,66)=5.23, \quad \mathrm{MSe}=.41]$, with no interaction $(\mathrm{F}=1.40)$.

\section{Discussion}

These results indicate that deep processing tasks led to better performance than did shallow tasks, even with an intentional learning set. Furthermore, this was true for young as well as older children, indicating that the younger children had the ability to employ beneficial deep encoding strategies. However, there was still an age difference in amount recalled, even with deep processing tasks.

\section{EXPERIMENT 2}

The levels model also argues that breadth of encoding is beneficial to retention, as distinct from depth per se (Craik, 1977). It may be that young children not only encode less spontaneously at a semantic level, but that they also encode less broadly. In Experiment 2, a given subject had a deep (shallow) task throughout, but a different specific judgment was required for each of the study lists. For example, a subject in the deep processing condition had a different specific decision to make for each list, but always involving a deep feature. The interest here was still "deep" vs. "shallow" processing, but with varied experiences at a given level (Keller, Whitney, \& Mueller, 1979).

The main interest was the carry-over effects of encoding tasks on subsequent free (i.e., no orienting task) performance. Experiment 1 demonstrated that young children could utilize semantic content and benefit from deep tasks, if they had to explicitly perform the tasks. A question of critical interest is whether the benefits would continue if the demand characteristics were less structured. To answer this question, Experiment 2 had not only a final recall test, but also a transfer list that did not involve an orienting task during the study phase. If experience with multiple deep tasks activates strategies that enable broader encodings, then subjects with such experiences should continue to do well on a free transfer list.

\section{Method}

Subjects and Design. Fifty-four subjects were selected from the third and fifth grades of the same school as in Experiment 1, with average ages of 8.5 and 10.5 years, respectively. The design was a 3 by 2 factorial for task (deep, shallow, none) and grade (third, fifth).

Materials. Four 12-word lists were constructed from 48 highfrequency unrelated nouns. The lists were recorded and presented as in Experiment 1.

Immediate free recall. Subjects performed a different task of the same type (level) for each of the three study lists. The specific deep decisions involved (1) "living" or "nonliving," (2) "found in the home or not," and (3) "can the object be seen." The shallow tasks involved identifying (1) gender of voiœ, (2) the initial phoneme, and (3) the final phoneme. Control subjects pronounced the word aloud but did not have an orienting task.

Final free recall. The subjects were given $3 \mathrm{~min}$ to orally recall as many words as possible from all lists, following a 60-sec distractor task.

Transfer list. Following a $60-\mathrm{sec}$ distractor task after the final recall test, the subjects were given a fourth list. Each subject merely pronounced the words as they were presented. A $60-\sec$ oral test followed the single study trial.

\section{Results}

Immediate free recall. The deep-processing and notask conditions led to better recall than did the shallowprocessing condition (M $=.63, .59$, and .47 , respectively) $[\mathrm{F}(2,48)=7.59, \mathrm{MSe}=.05]$. Furthermore, the Task by Position interaction was significant $[\mathrm{F}(4,96)=2.91$, $\mathrm{MSe}=.04]$. Shallow tasks led to the worst recall at all positions; however, while the deep tasks led to the greatest middle and recency recall, the no-task condition produced the greatest primacy recall (see Table 2).

The grade main effect was marginally significant $[\mathrm{F}(1,48)=3.34, \mathrm{MSe}=.05, \mathrm{p}<.08]$, with third graders recalling less than fifth graders $(\mathrm{M}=.53$ and .60 , respectively). Except for the position main effect, indicating primacy and recency recall superior to middle recall $[F(2,96)=57.48, M S e=.04]$, no other effects were significant $(\mathrm{Fs}<1.31)$.

Short-term store recall. There were no significant effects in the analysis of number of items recalled from STS. Third graders showed a greater proportion of total recall from STS than fifth graders $[F(1,48)=4.56$, $\mathrm{MSe}=.02]$, and both the deep and no-task conditions led to lower STS proportions than did the shallowtask condition $[F(2,48)=4.98]$.

Table 2

Average Probability of Recall by Input Segment for Immediate Tests, Final Tests, and Transfer Task and Recall from Short-Term Storage (STS) During the Immediate Tests, by Orienting Task and Grade

\begin{tabular}{|c|c|c|c|c|c|c|c|c|c|c|c|c|c|c|c|c|c|c|}
\hline & \multicolumn{6}{|c|}{ Immediate Free Recall } & \multicolumn{6}{|c|}{ Final Free Recall } & \multicolumn{6}{|c|}{ Transfer Task } \\
\hline & \multicolumn{2}{|c|}{ Deep } & \multicolumn{2}{|c|}{ Shallow } & \multicolumn{2}{|c|}{ None } & \multicolumn{2}{|c|}{ Deep } & \multicolumn{2}{|c|}{ Shallow } & \multicolumn{2}{|c|}{ None } & \multicolumn{2}{|c|}{ Deep } & \multicolumn{2}{|c|}{ Shallow } & \multicolumn{2}{|c|}{ None } \\
\hline & 3 & 5 & 3 & 5 & 3 & 5 & 3 & 5 & 3 & 5 & 3 & 5 & 3 & 5 & 3 & 5 & 3 & 5 \\
\hline $\begin{array}{l}\text { Primacy } \\
\text { Middle } \\
\text { Recency }\end{array}$ & $\begin{array}{l}.57 \\
.39 \\
.81\end{array}$ & $\begin{array}{l}.57 \\
.57 \\
.87\end{array}$ & $\begin{array}{l}.41 \\
.20 \\
.70\end{array}$ & $\begin{array}{l}.41 \\
.36 \\
.76\end{array}$ & $\begin{array}{l}.59 \\
.36 \\
.76\end{array}$ & $\begin{array}{l}.74 \\
.40 \\
.69\end{array}$ & $\begin{array}{l}.30 \\
.23 \\
.22\end{array}$ & $\begin{array}{l}.41 \\
.36 \\
.44\end{array}$ & $\begin{array}{l}.28 \\
.13 \\
.26\end{array}$ & $\begin{array}{l}.33 \\
.29 \\
.31\end{array}$ & $\begin{array}{l}.41 \\
.22 \\
.24\end{array}$ & $\begin{array}{l}.39 \\
.24 \\
.20\end{array}$ & $\begin{array}{l}.72 \\
.30 \\
.67\end{array}$ & $\begin{array}{l}.56 \\
.49 \\
.55\end{array}$ & $\begin{array}{l}.72 \\
.42 \\
.61\end{array}$ & $\begin{array}{l}.78 \\
.40 \\
.72\end{array}$ & $\begin{array}{l}.33 \\
.39 \\
.83\end{array}$ & $\begin{array}{l}.61 \\
.44 \\
.61\end{array}$ \\
\hline Total & .59 & .67 & .44 & .51 & .57 & .61 & .25 & .40 & .22 & .31 & .29 & .28 & .56 & .53 & .58 & .63 & .52 & .56 \\
\hline $\begin{array}{l}\text { STS-Number } \\
\text { STS-Proportion }\end{array}$ & $\begin{array}{r}2.30 \\
.39\end{array}$ & $\begin{array}{r}2.44 \\
.34\end{array}$ & $\begin{array}{r}2.07 \\
.56\end{array}$ & $\begin{array}{r}2.04 \\
.41\end{array}$ & $\begin{array}{r}2.07 \\
.38\end{array}$ & $\begin{array}{r}2.04 \\
.35\end{array}$ & & & & & & & $\begin{array}{r}2.11 \\
.44\end{array}$ & $\begin{array}{r}2.22 \\
.43\end{array}$ & $\begin{array}{r}1.78 \\
.36\end{array}$ & $\begin{array}{r}1.89 \\
.34\end{array}$ & $\begin{array}{r}2.89 \\
.67\end{array}$ & $\begin{array}{r}2.33 \\
.45\end{array}$ \\
\hline
\end{tabular}


Final free recall. Third graders recalled less than fifth graders $[F(1,48)=5.95, \mathrm{MSe}=.04]$. The Task by Grade interaction was marginally significant $[\mathrm{F}(2,48)=$ $2.43, \mathrm{MSe}=.040, \mathrm{p}<.10]$, as third and fifth graders did not differ with no task $(M=.29$ and .27 , respectively), but fifth graders were superior with deep $(\mathrm{M}=.25$ and $.40)$ and shallow tasks $(M=.22$ and .31$)$. The position main effect $[F(2,96)=5.64, \mathrm{MSe}=.03]$ showed more primacy than middle or recency recall $(\mathrm{M}=.35, .25$, and .28). No other effects were significant (Fs $<1.43)$.

Transfer task. The only significant effect in transfer was the position main effect $[\mathrm{F}(2,96)=115.38, \mathrm{MSe}=$ $.20]$, indicating positive primacy and recency relative to middle items for both grade levels. Neither the grade nor task main effects, nor their interaction, was significant $(\mathrm{Fs}<1.43)$, and neither interacted with position (Fs $<1.21)$. Similarly, there were no significant effects in the analyses of STS recall.

\section{Discussion}

The results of Experiment 2 generally replicated those of Experiment 1, where the two studies overlap. Any exceptions may be due to procedural differences, notably list content (since primacy-recency effects are not as pronounced with related words as with unrelated items). The Task by Position interaction in immediate recall in Experiment 2, and other results involving serial position in immediate and final recall, suggest deployment of differential processing over serial position in a manner similar to adults. Thus, it seems that children at these age levels experience the automatic effects on memory due to the differential type of processing that the levels model implies.

It appears, however, that forced orienting experiences do not prime more general memory strategies. On the transfer task, neither age level showed any residual benefit due to prior experiences. The comparability of the no-strategy and deep-task groups indicate that much of the "depth effect" is not a true benefit for deep processing, but rather a hindrance imposed by the shallow tasks, as has been found with young adults (Keller et al., 1979). The equivalence of the deep and no-task conditions also indicates that effective self-initiated strategies were present in the no-task condition, at both age levels, even without the support of overt orienting decisions.

The failure to observe residual depth effects for transfer performance may indicate that the processes involved in semantic classifications, while "helpful" (in contrast to nonsemantic tasks), are not flexible enough to be generally useful when "forced" on the learner. This would be consistent with the equivalence of the no-task and deep conditions in the earlier phases discussed above. Such an interpretation implicates a problem for the levels model per se and is not especially a developmental issue. Alternatively, it could be that children simply do not continue to employ these specific strategies without direct involvement because they do not perceive the value, that is, a "metamemory" problem (Brown, 1979).

\section{REFERENCES}

Battig, W. F., \& Montague, W. E. Category norms for verbal items in 56 categories: A replication and extension of the Connecticut category norms. Journal of Experimental Psychology Monograph, 1969, 80(No. 3, Pt. 2).

Brown, A. L. Theories of memory and the problems of development: Activity, growth, and knowledge. In L. S. Cermak \& F. I. M. Craik (Eds.), Levels of processing and human memory. Hillsdale, N.J: Erlbaum, 1979.

CraIK, F. I. M. Depth of processing in recall and recognition. In S. Dornic (Ed.), Attention and performance (Vol. 6). Hillsdale, N.J: Erlbaum, 1977.

Flavell, J. H. Developmental studies of mediated memory. In H. W. Reese \& L. P. Lipsitt (Eds.), Advances in child development and behavior (Vol. 5). New York: Academic Press, 1970.

Geis, M. F., \& HALL, D. M. Encoding and incidental memory in children. Journal of Experimental Child Psychology, 1976, 22, 58-66.

Hyde, T. S., \& JENKins, J. J. Recall for words as a function of semantic, graphic, and syntactic orienting tasks. Journal of Verbal Learning and Verbal Behavior, 1973, 12, 471-480.

JABLONSk , E. M. Free recall in children. Psychological Bulletin, 1974, 81, 522-539.

Keller, K. E., Whitney, S. M., \& Mueller, J. H. Variation in orienting tasks for immediate and free recall. American Journal of Psychology, 1979, 92, 293-305.

MurPhy, M. D., \& Brown, A. L. Incidental learning in preschool children as a function of level of cognitive analysis. Journal of Experimental Child Psychology, 1975, 19, 32-47.

Sykes, D. H. Stimulus processing and recognition memory in children. British Journal of Psychology, 1976, 67, 429-438.

Tulving, E., \& Colotla, V. Free recall of trilingual lists. Cognitive Psychology, 1970, 1, 86-98.

W ATE RS, H. S., \& W WTERS, E. Semantic processing in children's free recall: Evidence for the importance of attentional factors and encoding variability. Journal of Experimental Psychology: Human Learning and Memory, 1976, 2, 370-380.

Weiss, S. L., Robinson, G., \& Hastie, R. The relationship of depth of processing to free recall in second and fourth graders. Developmental Psychology, 1977, 13, 525-526.

(Received for publication June 8, 1979.) 